\title{
Evaluation of Different Methods for Hygienic Microbiological Control from the Working Surfaces in the Microbiological Laboratories
}

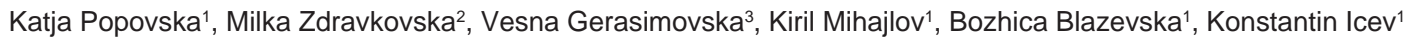 \\ ${ }^{1}$ Institute for Microbiology and Parasitology, Faculty of Medicine, University "Ss Cyril and Methodius", Skopje, Republic of \\ Macedonia; "Institute for Epidemiology and Biostatistics, Faculty of Medicine, University "Ss Cyril and Methodius", Skopje, Republic \\ of Macedonia; 'University Clinic for Nephrology, Faculty of Medicine, University "Ss Cyril and Methodius", Skopje, Republic of \\ Macedonia
}

\begin{abstract}
Citation: Popovska K, Zdravkovska M, Gerasimovska V, Mihajlov K, Blazevska B, IcevK. Evaluation of Different Methods for Hygienic Microbiological Control from the Working Surfaces in the Microbiological Laboratories. Maced J Med in the Microbiological Laboratories. Maced J Med Sci. 2011 Sep 30; 4(3):240-244. http://dx.doi.org/

Key words: Environmenth; biomase; plating methods; cultivating methods; hygienic control.

Correspondence: Prof. Dr. Katja Popovska. Institute for Microbiology and Parasitology, Faculty of Medicine, University "Ss Cyril and Methodius", s katja, Repulthome.mk

Received: 03-Feb-2011. Revised: 02-Jun-2011; Accepted: 17-Jun-2010; Online first: 28-Aug-2011

Copyright: (c) 2011 Popovska K. This is an open access article distributed under the terms of the Creative Commons Attribution License, which permits unrestricted use, distribution, and (n) author and source are credited.

Competing Interests: The author have declared that no competing interests exist.
\end{abstract}

\section{Abstract}

Background: The role of the inter-hospital non-living environment in spreading of some infections is not universally accepted attitude, but still there is a proof that in some cases it is a risk factor for causing infections with some pathogenic microorganisms. Isolation of microorganisms from the non-living environment can significantly vary in reproducibility and sensitivity of different methods of collecting specimen and its cultivation.

Aim: In aim to develop and assess hygienic control strategies with incorporating better monitoring and improved cleaning, we have undertaken this survey in microbiological labs to offer better approach in infection control procedures for sampling specimens from inanimate environment in health care facilities.

Material and Methods: Three issues might have influence on isolation rates of the mircroorganisms: sampling technique, cultivation methods and professional behaviour of the staff regarding the recommendations and guidelines for hygiene of the workplace. Staphylococcus aureus was almost the only isolated opportunistic microorganism from the surfaces of the workplaces (five from ten), beside Enterococcus, and there was no obvious differentiation in isolation capability between both used swabs. Semi-quantitative method was used for cultivation of saprophytic bacteria. Average of cfu from all used nutrient media was used to estimate bio-mass.

Results: Mann-Whitney $U$ test has confirmed statistically significant differentiation between average of cfu (colony-forming unit) ( $p=0.0215)$ sampled with Quanti swab in comparison with wet traditional cotton swab. Plating with swab on trypticase soy agar showed a statistically significant difference between the number of cfu after $24 \mathrm{~h}$ and $48 \mathrm{~h}$ (Wilcoxon Matched Pairs Test: $Z=2.66 ; p=0.0076$ ). Plating with pouring on trypticase soy agar at $45^{\circ} \mathrm{C}$ revealed a statistically significant difference between the number of cfu after $24 \mathrm{~h}$ and $48 \mathrm{~h}$ (Wilcoxon Matched Pairs Test: $Z=2.52 ; p=0.01171$ ).

Conclusion: This survey suggests that pour plate method is a more sensitive and appropriate cultivation method for hygienic control in healthcare facilities.

\section{Introduction}

There is no universally accepted opinion about the role of the intra-hospital non-living environment in spreading of some infections, but still there is a proof that in some cases it is a risk factor for causing infections with some pathogenic microorganisms [1].

Many references in the last 2 decades [2-4] have pointed that isolation of MRSA (Methicillin Resistant Staphylococcus aureus) from colonised and infected patients are connected with its isolation from surfaces of 
the non-living environment in the same units $[3,5,6]$. It is known that Staphylococcus aureus can survive well in the non-living environment, especially the epidemic strains [7]. It's not quite clear how the presence of MRSA in the non-living environment influences on the level of infections, but still there are conclusions that by regular and thorough cleaning as well as by exploring of the nonliving environment, incidence of infections with MRSA can be decreased from 3.45 to $0.5 /$ month [8]. In the Netherlands, [9] the rate of blood infections is decreased to only $1 \%$ by using the so-called approach "seek and destroy" that demands strict isolation of all colonised and infected patients in order to eliminate MRSA from the non-living environment.

Isolation of microorganisms from the non-living environment can significantly vary in reproducibility and sensitivity of different methods of collecting specimen and its cultivation.

There are two approaches of collecting specimen from the non-living environment: plate contact-method and swab-method. Plate contact-method is more sensitive than the swab-method, but it can be used on flat surfaces only. Swab-method can complement the contact-method for asperities and for places not easily reached. After collecting, the swab can be inoculated into or on the culture medium directly, but it shows variability depending on medium for moisten swab and the pressure being used during collecting the specimen $[6,10]$. Type of the culture medium has also influence the possibility of isolation of MRSA from the environment, because if non-specific culture mediums are being used, MRSA colonies can become covered with many other bacterial colonies when the surface is highly contaminated.

The aim of this survey was to develop and assess hygienic control strategies with incorporating better monitoring and improved cleaning in microbiological labs and to offer better approach in infection control procedures for sampling specimens from inanimate environment in health care facilities.

\section{Material and Methods}

The hygienic control of working surfaces in microbiological laboratories in 10 working places (laboratories) has been done (front desk, interventions room, laboratory for urogenital infections, laboratory for enteric infections, laboratory for respiratory infections, laboratory for anaerobic infections, laboratory for intra- hospital infections, laboratory for parasitology, laboratory for serology, plating room).

Three issues might have influence on isolation rates on the indicated microorganism: sampling technique, culture methods and professional behaviour of the staff regarding the recommendations and guidelines for hygiene of the workplace.

\section{Collecting the specimen}

\section{Traditional cotton swab}

Plastic swab with cotton tip is moisten in sterile Ringer's solution just before use, then the extra liquid is

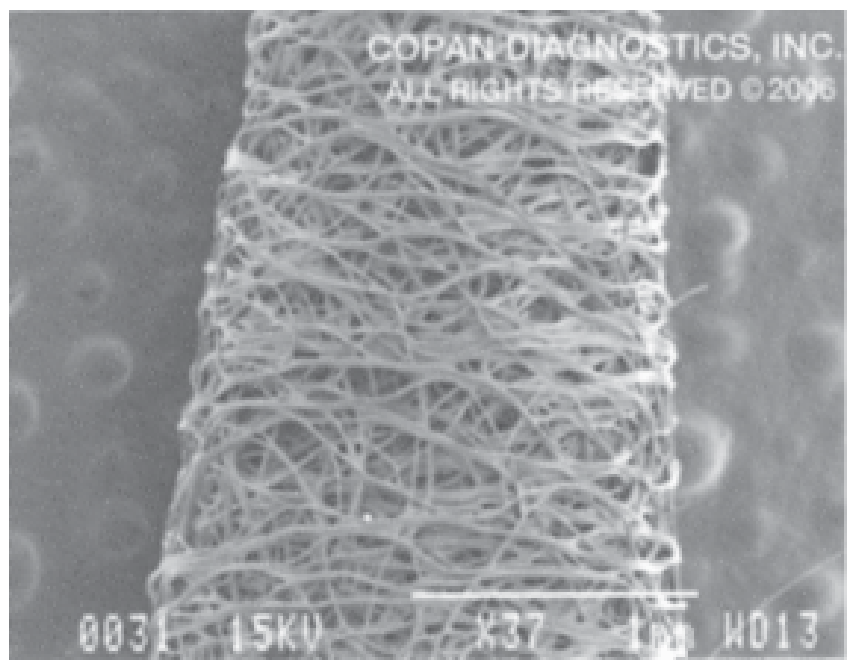

Figure 1: Hygienic cotton swab.

separated by mild pushing of the tip on the walls of the test tube. With permanent rotations of the swab between the fingers, it is moved in zig-zag lines on the workplace

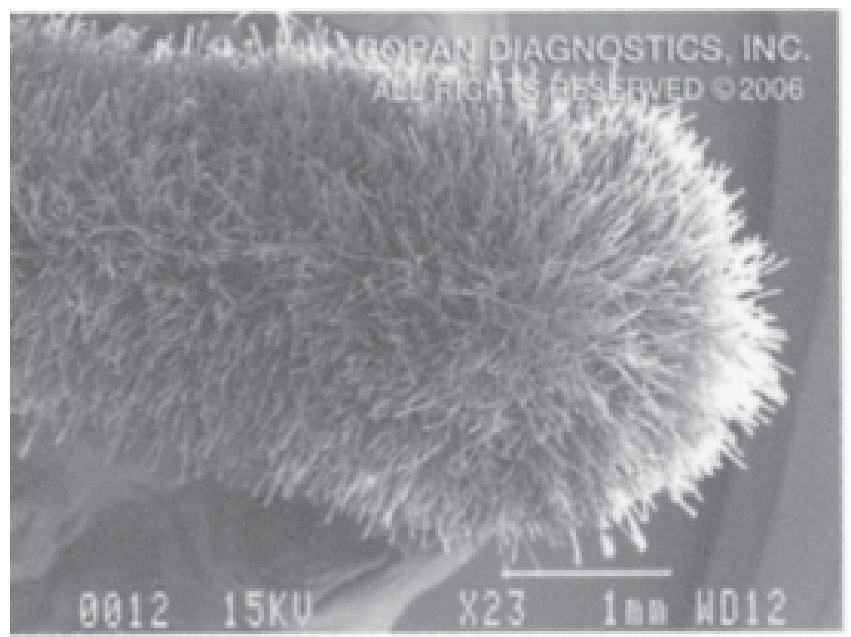

Figure 2: Quanti swab. 
to collect specimen. Specimens were collected all over the surface of working benches which are with standard dimensions (60 x $100 \mathrm{sm})$. Two specimens from each workplace were taken in a period of 15 minutes in order to get an average of cfu.

\section{Quantiswab(BioMérieux Marcyl'Etoile, France)}

The procedure of collecting from the surface is the same as the one with wet cotton swab. The only difference is the swab tip material; in this case nylon microfiber, with extraordinary hydraulics capillarity characteristics.

\section{Culture methods}

\section{Direct inoculation with the swab}

The collected specimens with wet cotton swabs [7] or with Quanti swabs have been planted on the surfaces of Columbia agar, Trypticase Soy Agar (TSA) (Oxoid UK) and dextrose broth.

\section{Inoculation with pouring into the culture medium}

The collected specimens with the cotton swabs [7] are submerged in $10 \mathrm{ml}$ Ringer's solution and then are being put in the vortex (10 sec/2000). One $\mathrm{ml}$ from the suspension is poured into Petri dish and then $20 \mathrm{ml}$ of Trypticase Soy Agar (cooled at $45^{\circ} \mathrm{C}$ ) is being added. After that, the dish should be mixed slightly, to distribute the bacteria evenly and is being incubated at $37^{\circ} \mathrm{C} / 24 \mathrm{~h}$. In the end, colonies are counted.

\section{Background}

Education and training of environmental and personal hygiene was conducted in the previous 6month period, including all employees at the Institute of Microbiology. Training course was undertaken every Monday morning before starting the routine work. Educational course was followed by a survey.

\section{Without announcing}

Specimens were collected during the break, after the routine lab work, when the working places are expected to be left safe and clean. Laboratory workers were not informed when collection of the specimens was done.

\section{With announcing}

Specimens were collected in the same way as previously described, but this time lab workers were informed that hygiene control of their working places was going to be done.

\section{Results}

Staphylococcus aureus was almost unique conditional pathogenic bacterium from the inanimate surfaces in the five investigated places (Table 1). All isolates were methicillin sensitive.

Table 1: Comparative results of conditional pathogenic bacteria with different types of swabs.

\begin{tabular}{|c|c|c|c|c|}
\hline \multirow[b]{2}{*}{ Place of collecting } & \multicolumn{2}{|c|}{ Wet cotton swab } & \multicolumn{2}{|c|}{ Quanti swab } \\
\hline & $\begin{array}{c}\text { Without } \\
\text { announcing }\end{array}$ & $\begin{array}{c}\text { With } \\
\text { announcing }\end{array}$ & $\begin{array}{c}\text { Without } \\
\text { announcing }\end{array}$ & $\begin{array}{c}\text { With } \\
\text { announcing }\end{array}$ \\
\hline $\begin{array}{l}\text { Laboratory for } \\
\text { respiratory infections }\end{array}$ & S.aureus MS* & 0 & S.aureus MS & 0 \\
\hline $\begin{array}{l}\text { Laboratory for anaerobic } \\
\text { infections }\end{array}$ & 0 & 0 & S.aureus MS & 0 \\
\hline $\begin{array}{l}\text { Laboratory for uroge nital } \\
\text { infections }\end{array}$ & S.aureus MS & 0 & 0 & 0 \\
\hline Interventions room & S.aureus MS & 0 & S.aureus MS & 0 \\
\hline Front desk & Enterococcus & 0 & $\begin{array}{l}\text { S.aureus MS } \\
\text { Enterococcus }\end{array}$ & 0 \\
\hline
\end{tabular}

*MS (Methicilin sensitive).

Table 1 and 2 present average of cfu from different types of swabs from ten workplaces that can be contaminated with biological material during the process of routine manipulation of technicians or microbiologists. Table 1 shows that Staphylococcus aureus was almost the only isolated opportunistic microorganism from the surfaces of the working desks (five from ten), beside Enterococcus, and there was no obvious difference in isolation capability between both used swabs.

Table 2 presents the remaining five surfaces without opportunistic pathogens on them, checked semiquantitatively for the amount of saprophytic flora. MannWhitney test was used to confirm whether there was significance in the differentiation of isolated biomase by both swabs. Semi-quantitative method was used for cultivation of saprophytic bacteria and correlated significantly with sampling technique and time of sampling (Table 2).

Table 2: Results from the semi-quantitative analysis of nonliving environment - without/with announcing.

\begin{tabular}{|c|c|c|c|c|}
\hline \multirow{3}{*}{ Place of collecting } & \multicolumn{4}{|c|}{ Number of colonies (after 48h) } \\
\hline & \multicolumn{2}{|c|}{ Wet cotton swab } & \multicolumn{2}{|l|}{ Quanti swab } \\
\hline & $\begin{array}{l}\text { Without } \\
\text { announcing }\end{array}$ & $\begin{array}{l}\text { With } \\
\text { announcing }\end{array}$ & $\begin{array}{l}\text { Without } \\
\text { announcing }\end{array}$ & $\begin{array}{l}\text { With } \\
\text { announcing }\end{array}$ \\
\hline $\begin{array}{l}\text { Laboratory for enteric } \\
\text { infections }\end{array}$ & 2 & 0 & 75 & 0 \\
\hline $\begin{array}{l}\text { Laboratory for intra } \\
\text { hospital infections }\end{array}$ & 12 & 0 & 22 & 0 \\
\hline Laboratory for serology & 7 & 0 & 40 & 0 \\
\hline Front desk & 10 & 0 & 50 & 0 \\
\hline Plating room & 1 & 0 & 10 & 0 \\
\hline
\end{tabular}

http://www.mjms.ukim.edu.mk 
Table 3: Average number of CFU after $48 \mathrm{~h}$ of incubation.

\begin{tabular}{cccc}
\hline Method & Average & SD & Mann-Whitney U Test \\
\hline Wet cotton swab & 6.4 & 4.8 & $\mathrm{Z}=-2.29$ \\
Quanti swab & 39.4 & 22 & $\mathrm{p}=0.0215$ \\
\hline
\end{tabular}

Mann-Whitney Utesthas confirmed a statistically significant difference between average of cfu $(p=0.0215)$ sampled with quanti swab in comparison with wet traditional cotton swab (Table 3, Table 4 and Figure1).

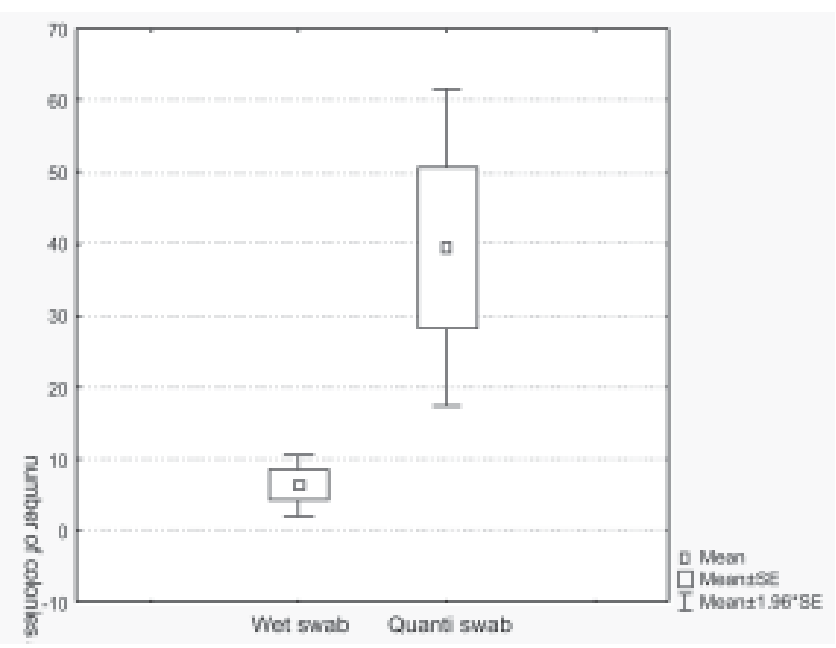

Figure 3: Average number of CFU after $48 \mathrm{~h}$ of incubation.

Plating with swab on trypticase soy agar showed a statistically significant difference between the number of cfu after 24h and $48 \mathrm{~h}$ (Wilcoxon Matched Pairs Test: $Z=2.66 ; p=0.0076)$.

Plating with pouring on trypticase soy agar at $45^{\circ} \mathrm{C}$ showed a statistically significant difference between the number of cfu after $24 \mathrm{~h}$ and $48 \mathrm{~h}$ (Wilcoxon Matched Pairs Test: $Z=2.52 ; p=0.01171$ ) (Table 4).

Table 4: Influence of planting methodology over quantitative and qualitative results of opportunistic microorganisms.

\begin{tabular}{|c|c|c|c|c|}
\hline \multirow[b]{2}{*}{ Place (lab/cabinet) } & \multicolumn{2}{|c|}{$\begin{array}{l}\text { Surface plating with swab } \\
\text { (number of colonies) }\end{array}$} & \multicolumn{2}{|c|}{$\begin{array}{l}\text { Pour plate method } \\
\text { (number of colonies) }\end{array}$} \\
\hline & After $24 \mathrm{~h}$ & After $48 \mathrm{~h}$ & After $24 \mathrm{~h}$ & After $48 \mathrm{~h}$ \\
\hline Interventions (outpatients) & 0 & 2 & 1 & 3 \\
\hline Serology & 0 & 2 & 0 & 0 \\
\hline Urogenital laboratory & 0 & 4 & 1 & $>50$ \\
\hline Parasitology & 0 & $1(\mathrm{mold})$ & $>20$ & $>30$ \\
\hline Respiratory tract infections & 0 & 0 & 0 & 2 \\
\hline Deep tissue infections & 0 & 1 & 1 & $>20$ \\
\hline Gastrointestinal infections & 0 & $3(1 \mathrm{mold})$ & 4 & 8 \\
\hline $\begin{array}{l}\text { Front desk - administrative } \\
\text { procedure }\end{array}$ & 1 & 20 & 0 & 2 \\
\hline $\begin{array}{l}\text { Cabinet for plating } \\
\text { samples }\end{array}$ & 0 & 5 & 0 & 1 \\
\hline $\begin{array}{l}\text { Samples important for } \\
\text { nosocomial infections } \\
\text { (environment/patients) }\end{array}$ & 0 & 1 & 0 & 0 \\
\hline
\end{tabular}

Mann-Whitney $U$ test showed a significant difference in cfu number, pour plate method over surface planting method after $24 \mathrm{~h}$ cultivation period $(Z=-1.97$; $p=0.0490)$. Cultivation period of $48 \mathrm{~h}$ revealed no significant difference $(Z=-0.64 ; p=0.5205)$.

\section{Discussion}

No matter how the swabs were taken, either by previous announcement or not, it is obvious from Table 1 that opportunistic-pathogenic bacteria were isolated equally from almost all working surfaces, and Staphylococcus aureus was prevailing bacteria.

Quanti swab is not more sensitive technique in recovering pathogenic bacteria compared with traditional swabs since it has no influence over the number or species recovering conditional bacteria from inanimate surfaces.

On the other hand, sampling technique shows significant difference over semi-quantitative isolation of saprophytic bacteria, quanti swab over traditional swabs. Mann-Whitney $U$ test has confirmed a statistically significant difference between average number of cfu ( $p$ $=0.0215$ ) sampled with quanti swab in comparison with wet traditional cotton swab. This is to be expected since quanti swab has superior performance due to its exceptional hydraulic capillary action that can improve recovery and release capacity between $60-90 \%$ against traditional swabs. Traditional swabs trap microorganisms in their winded matrix and it is difficult to realise them, in comparison with quanti swab flocking design which is able to recover and realise microorganisms more easily.

In both cases of recovering saprophytic or conditional pathogenic bacteria awareness of the staff appears to be a very important factor that influences the environmental hygiene. In our case, this was obvious by presenting completely negative isolation when laboratory workers were informed about the investigation. Plating with swab on trypticase soy agar showed a statistically significant difference between the number of cfu after 24h and 48h (Wilcoxon Matched Pairs Test: $Z=2.66 ; p$ $=0.0076$ ). Plating with pouring on trypticase soy agar at $45^{\circ} \mathrm{C}$ revealed a statistically significant difference between the number of cfu after $24 \mathrm{~h}$ and $48 \mathrm{~h}$ (Wilcoxon Matched Pairs Test: $Z=2.52 ; p=0.01171$ ). This is to be expected according to the concept "environmentally altered microorganisms" (Perry and Rammelkamp) which means that microorganisms from inanimate environment need some time to become viable and then start dividing 
themselves [11, 12].

Mann-Whitney $U$ test found a significant difference in cfu number, the pour plate method over surface planting method after $24 \mathrm{~h}$ cultivation period ( $Z$ $=-1.97 ; p=0.0490)$. Cultivation period of $48 \mathrm{~h}$ showed no significant difference $(Z=-0.64 ; p=0.5205)$.

However, the pour plate method appears to have capability to provide a higher number of cfu from the three investigated surfaces (labs for urogenital and anaerobic infections, as well as lab for parasitology), which might influence the interpretation of microbiological results referring to hygienic control of inanimate environment (Table 4).

This survey suggests that pour plate method is a more sensitive and appropriate cultivation method for hygienic control in healthcare facilities.

The results obtained in this study induced the need of implementation of continuous training of the laboratory staff and periodical monitoring over the hygiene of the working places in the Institute of Microbiology, by using the quanti swab.

\section{References}

1. Lewis T, Griffith C, Gallo M, Weinbern M. A modified ATP benchmark for evaluating the cleaning of some hospital environmental surfaces. J Hops Infect. 2008;69:156-163.

2. Boyce JM, Causey WA. Increasing occurrence methicillinresistant Staphylococcus aureus in the United States. Infect Control. 1982;3:377-383.

3. Voss A, Milatovic D, Walrauch-Schwrch C, Rosdahl VT,
Braveni I. Methicillin resistant Staphylococcus aureus in Europe. Eur J Clin Microbiol. 1994;13:50-55.

4. Talon $\mathrm{D}$. The role of hospital environment in the epidemiology of multi-resistant bacteria. J Hosp Infect. 1999;43:13-17.

5. Rampling A, Wiseman S, Davis L, et al. Evidence that hospital hygiene is important in the control of methicillin resistant Staphylococcus aureus. J Hosp Infect. 2001;49:109116.

6. Obee P, Griffith CJ, Cooper RA, Bennion NE. An evaluation of different methods for the recovery of methicilin-resistant Staphylococcus aureus from environmental surfaces. J Hosp Infect. 2007;65:35-41.

7. Ayliffe GA, Buckles A, Caswell MW, et al. Revised guidelines for the control of methicillin-resistant Staphylococcus aureus infection in hospitals. J Hosp Infect. 1998;39:253-290.

8. Frank U. Prevention and control of methicillin-resistant Staphylococcus aureus (MRSA) In: Holland : Fluit AC, Schmitz FJ, editors. MRSA: current perspectives. Witshire: Cromwell Press limited, 2003:317-336.

9. Moore G, Grifith CJ. A comparison of surface sampling methods for detecting coli forms on food contact surfaces. Food Microbiol. 2002;19:1466-1471.

10. Scherlock O, O'Connell N, Creamer E, Humphreys H. I s it rely clean? An evaluation of the efficacy of four methods for determining hospital cleanliness. J Hops Infect. 2009;72:140146.

11. Perry WD, Siegel AC, Rammelkamp CH Jr, Wannamaker LW, Marple EC. Transmission of group A streptococci. I. The role of contaminated bedding. Am J Hyg. 1957;66(1):85-95.

12. Perry WD, Siegel AC, Rammelkamp CH Jr. Transmission of group A streptococci. II. The role of contaminated dust. Am J Hyg. 1957;66(1):96-101. 